Pain. 2018 March ; 159(3): 603-609. doi:10.1097/j.pain.0000000000001141.

\title{
Itch and Neuropathic Itch
}

Junichi Hachisuka ${ }^{1,2}$, Michael C. Chiang ${ }^{1,2}$, and Sarah E. Ross ${ }^{1,2, *}$

${ }^{1}$ Department of Neurobiology, University of Pittsburgh, Pittsburgh, PA 15213, USA

2Pittsburgh Center for Pain Research, University of Pittsburgh, Pittsburgh, PA 15213, USA

\section{THE SENSE OF ITCH}

Itch is a distinct sensation that provokes the desire to scratch, and scratching typically causes itch to subside, at least temporarily. This itch-scratch sensorimotor response to an aversive agent is highly conserved across the animal kingdom: mammals itch, birds itch, even fish, thought lacking appendages, will rub themselves against rocks (or use their tails) to scratch themselves. Whether insects itch is less clear, but flies show site-directed grooming behavior in response to the application of an irritant to the wing - a behavior that is likely akin to itch. Of course, not all animals show itch behavior. For instance, rather than scratching an aversive agent away, worms will simply retreat to evade harm. Nevertheless, the high degree of conservation of itch-induced scratching across all vertebrates as well as some invertebrates implies that this behavior confers an important evolutionary advantage. So why do we itch?

Scratching an itch is thought to have at least three beneficial consequences. First, if the organism is able to detect a threat at the body's surface, such as a disease-carrying parasite, it can be scratched away. In addition, since the sensation of itch is highly aversive, the organism learns from past experience to avoid future exposures. Finally, the very act of scratching can help recruit the immune system, helping rid the body of an infectious agent. Each of these responses is thought to favor survival by protecting an organism from harm, hence the conservation of itch/scratch as a sensorimotor response.

As an aversive sensation that serves to protect the body, itch is conceptually similar to pain. However, there are a few notable distinctions between these two percepts. Whereas pain can be triggered from almost anywhere in the body, itch is only experienced where scratching is possible - at the body's surface [52]. Itch and pain elicit distinct behavioral responses: one scratches an itchy stimulus but withdraws from a noxious one. Furthermore, itch and pain can be differentially modulated. For instance, whereas mu opioids such as morphine reduce pain, this class of analgesics causes itch [4]. Finally, though they are both unpleasant, itch and pain are perceptually distinct sensations. These key differences imply that the neural circuits that give rise to itch must be distinct from those that give rise to pain. Understanding

\footnotetext{
*Corresponding Author: Sarah E. Ross, W1456 Biomedical Science Tower, 200 Lothrop St., Pittsburgh, PA 15213, saross@ pitt.edu.
} The authors declare no conflicts of interest. 
the coding of itch, and how it is distinguished from pain in the nervous system remains a major unanswered question.

\section{Neural basis of itch}

Itch and pain are thought to be elicited by activity in primary sensory afferents that have a relatively slow conduction velocity (C-fiber and A $\delta$ fibers) [35; 74]. However, the specific afferents that mediate itch remain a matter of controversy. There are primary afferent fibers that respond to pruritogens (itch-inducing agents) such as histamine and whose activity corresponds to the sensation of itch in humans [82]. It has thus been speculated that these fibers convey pruriception from the periphery to the nervous system, and these observations have been used to argue in favor of the existence of afferents that are selectively tuned for itch but not pain $[51 ; 77]$. Yet there are many observations, as described further below, that do not fit with this straight-forward explanation. As a result of these inconsistencies, it has been suggested that it is not simply the nature of the afferent but rather the pattern of activity from a given afferent or the combination of afferent activity from a population of afferents that gives rise to either itch or pain $[17 ; 52]$.

\section{Itch-selective afferents}

Perhaps the strongest evidence for the existence of itch-selective primary afferents comes from studies in mice, where at least two distinct populations have been implicated in itch. One of these populations is the MrgprA3-expressing population of unmyelinated afferents [49]. Genetic labeling of these neurons reveals that they selectively innervate the superficial skin, which would be predicted for itch-specific afferents. Moreover, selective activation of MrgprA3-expressing afferents using a chemogenetic strategy is sufficient for itch behavior, whereas ablation of these cells reduced (but did not eliminate) itch in response to a variety pruritogens [25]. A second population that appears to be involved are neurons that express Natriuretic polypeptide b (Nppb) [55]. Recent single cell profiling experiments have revealed that the Nppb population of primary afferents also expresses receptors for several pruritogens, such as interleukin 31 [62; 98]. Moreover, the Nppb- and MrgprA3-expressing sensory neurons are non-overlapping populations, and it is postulated that both of these afferent subtypes mediate itch.

The idea that two distinct populations of primary afferents mediate the response to pruritogens was predicted based on human studies, where it was long speculated that there are least two different kinds of itch: histamine-induced itch and non-histaminergic itch [44; 81]. Histamine is the main pruritogen that is responsible for hives (ulticaria), and histamine in the epidermis causes a pure sensation of itch, together with wheal and flare, which are thought to be mediated by the local release of substance P and CGRP from primary afferents $[21 ; 88]$. Studies using microneurography to look at the activity of single primary afferents in humans have identified a population of mechanically insensitive C-fibers with large cutaneous innervation territories that fire vigorously in response to histamine with a duration and intensity of their activity that matches the subject's description of the itch percept [82]. Thus, it is hypothesized that these afferents mediate histaminergic itch. In contrast, numerous pruritogens cause itch that is not associated with wheal and flare, and the absence of this axon-reflex is interpreted to indicate the involvement of non-peptidergic afferents. 
This so-called non-histaminergic itch has been elicited historically using cowhage (Mucana Pruriens), a tropical plant whose seed pods are coated with short hairs called spicules [85]. When cowhage spicules are inserted superficially into the skin, they cause a prickly itch that is mediated by a cysteine protease [45; 73]. Intriguingly, human microneurography experiments suggest that the primary afferents that respond to histamine and those that respond to cowhage are distinct [36]. Consistent with the idea of at least two populations of itch-tuned afferents, in a cunning experiment using a lidocaine-derivative that can only permeate active cells, Roberson et al. showed that blocking the activity of histamineresponsive afferents in mice does not inhibit the response to a non-histaminergic pruritogen [75].

\section{Population coding}

While there is good evidence suggesting the existence of at least two populations of primary afferent that respond to itch-inducing agents, these findings do not yet fully solve the puzzle of how specificity is achieved. For instance, microneurography experiments in humans show that histamine-responsive afferents also respond to algogens such as bradykinin with a similar magnitude and duration, so it is hard to envision a mechanism through which they could signal only pruriception [83]. The issue of specificity is also underscored by findings in monkeys in which the high prevalence of itch-responsive afferents (75\% for histamine) does not fit with the idea that pruriception and nociception are mediated by distinct sensory neurons [35]. Even in mouse, where two populations (MrgprA3 and Nppb) have been suggested to be itch-specific, it is not clear that all of the neurons in these populations signal itch and only itch. Finally, these two populations are not likely to be the only neurons that can signal itch since beta-alanine-induced itch is thought to occur via yet another nonoverlapping population: Mrgd-expressing afferents, which are a cutaneous population that is highly sensitive to mechanical input [48; 72]. Since primary afferents that respond to pruritogens but not algogens have been elusive, many have speculated that the solution to the question of itch versus pain must lay elsewhere, perhaps being encoded by activity at the population level together with differences in central connectivity $[17 ; 27 ; 28 ; 44]$.

\section{Spinal circuits of itch}

The primary afferents that convey pruriception from the periphery to the spinal cord target the superficial dorsal horn (lamina I and the outer region of lamina II) [78]. How this pruritoceptive input is integrated in these laminae is not yet clear. Several cell types in the dorsal horn are thought to be involved in mediating pruriception, including the neurons that express gastrin releasing peptide (GRP) and those that express its receptor (GRPR). Ablation of GRP neurons gives rise to mice with decreased itch and increased pain behaviors [93]. Moreover, inhibition of GRPR or ablation of the spinal neurons that express GRPR results in significantly decreased itch, with no changes in pain behaviors [38; 94; 95]. These and other studies have raised the possibility that pruritoception is conveyed from primary afferents to spinal projection neurons via a disynaptic pathway [55]. However, the reality is likely more complex, and precisely how GRP- and GRPR-expressing interneurons fit into neural circuits that integrate pruriception within the spinal cord remains unclear. 
The neurons that convey pruriception from the spinal cord to the brain are a subset of anterolateral tract (ALT) neurons, which target numerous brain structures including the rostral ventral medulla, the parabrachial nucleus, the cerebellum, and the thalamus [18] [44; 96]. However, the specific subset that is involved in conveying pruriception, as opposed to nociception, is not yet clear. Thus, while many groups have recorded from spinal (or trigeminal) output neurons that respond robustly to pruritogens, invariably such output neurons also respond to algogens $[10 ; 33 ; 34 ; 59 ; 89]$. Since we lack a satisfactory model to explain how information sent from the spinal cord to the brain could be itch-specific, many have concluded that the decoding of itch must occur within the brain rather than the spinal cord [44]. And yet the scratch reflex, which likely represents an itch behavior, is a spinal reflex [86]. Furthermore, the modality selective modulation of itch and pain by mu opioids is likely to occur at the level of the spinal cord rather than the brain [4]. Indeed, morphine was found to decrease the activity of trigeminothalamic neurons that appeared to be tuned for nociception, while increasing the activity in those that appeared tuned for pruritoception [58]. These findings suggest that, although the exact circuitry remains elusive, spinal cord integration of sensory input is sufficient for the basic decoding of itch versus pain.

\section{Supraspinal circuits of itch}

The specific neural circuits in the brain that integrate itch also remain poorly characterized. In general, the cerebral areas that are activated in response to pruritic or noxious stimuli are similar, and include the thalamus, primary and secondary somatosensory cortices, anterior cingulate cortex, prefrontal cortex, amygdala, periaqueductal grey [1; 11; 23; 57] (Figure 1). However, a few differences have been reported. For instance, whereas noxious heat drove bilateral activity in supplementary motor area (SMA) and the contralateral anterior cingulate cortex (ACC), intracutaneous histamine injections activated the ipsilateral SMA and contralateral ACC [13; 31]. Another study reported similar motor regions as well as limbic areas such as the anterior insula cortex (aIC) that were activated in response to itch and pain imagery. However, the right aIC exhibited greater connectivity to primary motor and premotor cortices during pain imagery, whereas the left aIC exhibited connectivity with motor regions such as the basal ganglia and tegmental area [56]. Such differences between itch and pain may be due, at least in part, to distinct motor plans that are triggered in response to either pruriceptive or nociceptive stimuli. Different types of itch (histaminergic and cowhage-induced) also activate similar patterns of activity within the brain. However, it has been reported that only cowhage-induced itch resulted in activity within the contralateral insula and claustrum [70]. Thus, conventional itch and prickly itch have somewhat distinct representations in the brain.

Itch, like pain, is thought to have multiple dimensions, including discriminative and aversive components. It is likely that the spinothalamic tract mediates discriminative aspects itch, whereas cerebral pathways conveying the affective aspects of itch may be mediated by evolutionarily ancient circuitry. In this regard, it is likely that the spinoparabrachial pathway, which projects to the lateral parabrachial nucleus, plays a critical role. The lateral parabrachial nucleus is thought to serve as an alarm system, warning the organism of potential threats [80]. Using a clever strategy, Rodriguez et al. genetically labeled the neurons in the parabrachial nucleus that responded to a noxious stimulus and showed that 
activation of this population was sufficient to drive affective behaviors, including aversion and vocalization [76]. One population that is likely involved in this response are those expressing calcitonin-gene-related peptide (CGRP), which are localized within the external lateral subdivision of the lateral parabrachial nucleus and have been indicated in the generation of fear memory to foot shock via its projection to the central amygdala [26]. Given the commonalities between itch and pain, it is likely that similar pathways mediate the aversive response to itch. Consistent with this possibility, inhibition of the parabrachial nucleus reduced pruritogen-evoked scratching behavior [60]. The degree to which the same or different populations of neurons in the parabrachial nucleus mediate the aversive responses to pain and itch remains to be determined.

\section{NEUROPATHIC ITCH}

When neurons (or glia) involved in integrating or conveying pruritoception anywhere in the peripheral or central nervous system become damaged, neuropathic itch can ensue [54]. This type of itch - neuropathic itch - is estimated to represent $8 \%$ of the total cases of chronic pruritus [92]. Moreover, itch is likely an underdiagnosed symptom of neuropathic conditions [7]. In some cases, neuropathic itch can be very severe, and unfortunately there is a dearth of effective treatments, underscoring that neuropathic itch as an important unmet clinical need [39].

Almost every neuropathic pain syndrome has a neuropathic itch counterpart that affects a segment of the afflicted patients [7]. Thus, many individuals with neuropathic pain suffer from itch in addition to pain. Specifically, in patients with neuropathic pain, itch is a feature in one-third of cases, with moderate to severe itch observed in $5-10 \%$ of patients [7]. There are other instances of neuropathic itch where itch is the prevailing symptom which occurs in the absence of pain (e.g., post-herpetic itch). Why itch, rather than pain, is a prominent feature of neuropathic states in some cases but not others remains unclear [66].

\section{Central sensitization of itch}

Like its pain counterpart, neuropathic itch can be amplified or exacerbated within the nervous system through a group of mechanisms collectively termed central sensitization. Many people with neuropathic itch develop so-called 'itchy skin' (alloknesis), a state in which innocuous touch or brush causes itch [87]. This type of sensitization is conceptually analogous to touch-evoked pain (allodynia), which often accompanies neuropathic pain. Both alloknesis and allodynia are thought to be mediated by the abnormal integration of low-threshold mechanoreceptor input within the spinal cord [41]. Sensitization can also occur to C-fiber input, giving rise to hyperalgesia (abnormally elevated response to noxious stimuli) or hyperknesis (abnormally elevated response to pruritic stimuli) [2]. Intriguingly, for patients with chronic pain, histamine is perceived as painful rather than itchy [5]. Conversely, for patients with chronic itch, noxious stimuli can be perceived as itch-inducing rather than painful $[63 ; 64 ; 99]$. These findings suggest that there are parallel mechanisms of sensory amplification for itch and pain that are likely mediated by plasticity within the central circuits. 


\section{Peripheral neuropathies as a cause of neuropathic itch}

The most common types of neuropathic itch are due to damage to primary afferents (Figure 1), which can occur as a consequence of infection of primary afferents, compression of nerve fibers, metabolic diseases or toxins that affect nerve fiber function, as well as rare genetic conditions.

One of the main causes of severe neuropathic itch is shingles (herpes zoster) [65]. This disease occurs upon reactivation of latent virus that remains in nerve cells following an infection of chickenpox (varicella zoster). Typically, one ganglion is affected, resulting in a painful rash in the corresponding dermatome. Although the immune system may clear the active virus within a few weeks, there is often long-term damage to the primary afferents that results in pain (post-herpetic neuralgia) or itch (post-herpetic itch) in the region of skin that is innervated by the damaged fibers [65]. These symptoms can be severe and persistent, lasting for months or years. It is estimated that $30 \%$ of people with post-herpetic neuralgia suffer from itch, and for reasons that are poorly understood, itch is more likely to be observed in proximal dermatomes (head and face) than in distal dermatomes [67] [71].

Occasionally, compression of nerves can cause very severe itch, which is typically localized to the region of skin that is innervated by the damaged nerve. These itch-associated conditions commonly include brachioradial pruritus due to damage to cervical (C3-C6) nerves, resulting in itch on the arms, and notalgia paraesthetica due to entrapment of dorsal rami of thoracic (T2-T6) nerves, resulting in itch on the back [92]. With these two conditions, itch is often the prevailing symptom. Though pain is a more common symptom, it is possible for itch to occur upon damage to almost any cutaneous nerve, resulting in itch that is typically accompanied by tingling and numbness within the innervated skin.

Generalized nerve fiber degeneration can also give rise to itch. This type of polyneuropathy can occur from uncontrolled diabetes mellitus, exposure to chemotherapeutic drugs, or alcohol abuse [53]. In these cases, primary afferents with longer axons, such as those that innervate distal tissues, are thought to be the most vulnerable, often resulting in itch of the feet. One-third of patients with peripheral neuropathies are estimated to suffer from itch [7].

Finally, there are rare instances when neuropathic itch is caused by a genetic disorder. For instance, with Fabry disease, an X-linked disorder caused by loss-of-function of agalactosidase, there is an accumulation of a glycolipid that exerts toxic effects in several cell types, including peripheral nerves [53]. As a consequence of this nerve damage, individuals with Fabry disease often experience itching, numbness, tingling, burning, pain, and cold sensitivity. A second, rare genetic cause of neuropathic itch is due to a variant in $S C N 9 A$, which encodes a voltage-gated sodium channel that is expressed in sensory neurons [19; 91]. In particular, the $1739 \mathrm{~V}$ variant gives rise to a sodium channel with slower inactivation kinetics. Although most people with this variant have small fiber neuropathy with paroxysmal pain, in some people, this variant causes attacks of itch rather than pain. The neuropathic itch in these individuals can be precipitated by warmth and spicy food, suggesting a possible involvement of TRPV1. 


\section{What causes neuropathic itch due to peripheral neuropathies?}

Irrespective of the underlying cause, one of the hallmarks of peripheral neuropathic itch that distinguishes it from inflammatory itch is nerve density: neuropathic itch is typically associated with a decrease in the density of nerve fibers that innervate the epidermis, whereas inflammatory itch is associated with increased cutaneous innervation [54; 71]. Indeed, in a famous case of post-herpetic itch, only $5 \%$ of epidermal nerve fibers remained leading some to speculate that central mechanisms must be involved [68]. The idea that fewer fibers could give rise to more itch is somewhat counter-intuitive. Nevertheless, it is clear that activity within these afferents plays an essential role in neuropathic itch due to peripheral neuropathies since transient inhibition of this input with topical lidocaine alleviates itch [65]. The degree to which this type of itch is due to pathological activity in the remaining afferents versus an abnormal pattern of sensory input that is aberrantly integrated by the central nervous system is unknown.

\section{Peripheral neuropathic itch: insight from animal models}

All primary afferents use glutamate as an excitatory neurotransmitter (and some also release peptides, such as substance $\mathrm{P}$ and calcinonin gene related peptide) [30; 101]. With the goal of blocking glutamate release from these sensory neurons, two different groups selectively removed the vesicular glutamate transporter type 2 (VGLUT2) in either all or in subsets of primary afferents $[43 ; 50]$. Since VGLUT2 is the only glutamate transporter in most highthreshold afferents and therefore required for glutamatergic neurotransmission, it was not surprising that mice lacking VGLUT2 in these cells showed reduced responses to noxious mechanical, thermal and chemical input. Unexpectedly, however, these mice also showed spontaneous itch behavior and elevated responses to pruritogens. Thus, decreased pain was associated with increased itch. These findings underscore the idea that itch can occur as a result of an abnormal pattern of activity in populations of primary afferents.

\section{Central lesions as a cause of neuropathic itch}

Though rare, central lesions can also result in neuropathic itch (Figure 1). These include tumors or strokes such as those affecting the lateral medulla [84]. Prion disease, such as Creuzfeldt-Jakob disease can present with pruritus particularly for patients with the familial CJD due to a mutation in the gene encoding Prion Protein (PRNP) [14]. Intriguingly, Scrapie, another prion disease found in sheep and goats, is so-named because affected animals scrape themselves against objects to relieve itch [42]. Tumors, abscesses or lesions that affect the spinal cord can also result in pathological itch in the corresponding region of skin. For instance, when vascular malformations (cavernous hamangiomas) occur in the spinal cord, neuropathic itch can ensue $[3 ; 15 ; 46]$. The underlying cause of itch with these vascular malformations is not clear, but could involve either loss of inhibition or ectopic activity due to gliosis and hemosiderin deposition [20].

Demyelinating disorders can cause short attacks of itch over many regions of the body. In patients with multiple sclerosis, the incidence of itch is low $(\sim 5 \%)$; however, one- to twothirds of patients with neuromyelitis optica report pruritus which precedes other neurological symptoms $[22 ; 29 ; 54]$. Neuromyelitis optica is a relapsing neuroinflammatory disease of the central nervous system that is associated with aquaporin-4 (AQP4) autoantibody [47]. AQP4 
is expressed in astrocytes of the white and gray matter along the whole spinal cord with markedly higher intensity in the superficial lamina of the dorsal horn [69]. Magnetic resonance imaging revealed that itch in these patients corresponded to the level of spinal lesion [61].

\section{Central neuropathic itch: insight from animal models}

As observed in humans, pathological changes within the dorsal horn in animal models can result in neuropathic itch. Specifically, cell death in the dorsal horn due to intraspinal injections of the excitotoxic agent quisqualate results in both elevated responses to noxious stimuli as well as abnormal biting and licking behavior that is suggestive of itch [20;100]. Similarly, ablation or inhibition of glycinergic neurons in the dorsal horn results in both elevated pain and itch behaviors [24]. One of the glycinergic subtypes that may be involved in the inhibition of itch are those that can be genetically tagged with the NPY-Cre allele, since ablation of these cells resulted in spontaneous itch behavior and increased mechanically-induced itch [8].

Mice lacking the transcription factor Bhlhb5 (also known as Bhlhe22) develop self-inflicted skin lesions due to excessive licking and scratching [79] that is now recognized to be due to severe neuropathic itch. This conclusion was based on a series of studies from our lab, first showing that Bhlhb5 mutant mice showed dramatically enhanced itch behaviors in response to a variety of pruritogens [79]. Next, through a combination of conditional ablation and fate mapping approaches, we provided evidence that the abnormal itch in Bhlhb5 mutant mice is due to the loss of a specific population of inhibitory neurons in the dorsal horn that require Bhlhb5 for survival [79]. We called these cells B5-I neurons since they are Inhibitory

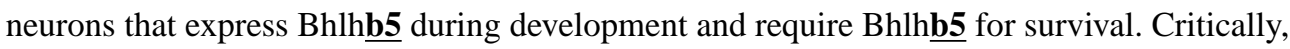
we showed that transient inhibition of B5-I neurons causes spontaneous scratching behavior [37]. These findings suggested that one of the normal functions of B5-I neurons is to inhibit itch [90] (Figure 2).

Most recently, we discovered that B5-I neurons differentiate into two subsets of inhibitory neurons in the dorsal horn: those that express nNOS and those that express dynorphin [37] [12]. The dynorphin population is particularly attractive as a population that inhibits itch because dynorphin is a kappa opioid receptor agonist, and there is strong precedent for the involvement of kappa agonists in the inhibition of itch [32; 40; 97]. Furthermore, our work revealed that kappa opioid receptor tone at the level of the spinal cord bidirectionally modulates itch: intrathecal kappa agonists inhibit itch whereas intrathecal kappa antagonists exacerbate itch [37]. Together these findings suggest that dynorphin-expressing inhibitory interneurons in the superficial dorsal horn function to inhibit itch, and that mice lacking these cells develop severe neuropathic itch that is central in origin [12] (Figure 2). Consistent with this idea, the transplantation of inhibitory interneurons into the dorsal horn can reverse the neuropathic itch in Bhlhb5 mutant mice [9] [6].

\section{Treatments for neuropathic itch}

As of yet, there have been no clinical studies to test putative therapies for neuropathic itch. Given the similarities in the neural circuits of itch and pain, many treatments for neuropathic 
pain have been tried on people suffering from neuropathic itch, and there is abundant anecdotal evidence that many of the treatments, such as capsaicin patches and gabapentin, may also be partially effective for the treatment of neuropathic itch in some cases. However, a key difference between itch and pain that should be underscored is that mu opioid receptor agonists such as morphine exacerbate and even trigger itch rather than alleviate it [4]. In this regard, it is interesting to speculate that distinct opioids may be involved in modulating distinct aspects of somatosensation. In particular, the inhibition of itch by kappa agonists may be a counterpart of the inhibition of pain by mu agonists. The kappa agonist nalfurafine is used clinically for the treatment of uremic pruritis and cholestatic pruritus in Japan [16]. Whether the kappa agonists will similarly prove effective for the treatment of neuropathic itch remains unknown.

\section{Acknowledgments}

The authors of this publication were supported by the National Institute of Arthritis and Musculoskeletal and Skin Diseases of the National Institutes of Health under Award Number R01 AR063772 to S.E.R, as well as the National Institute of Neurological Disorder and Stroke under Award Number NS02372925 to S.E.R. and by NIH grants F30NS096860 and to M.C.C..

\section{References}

1. Apkarian AV, Bushnell MC, Treede RD, Zubieta JK. Human brain mechanisms of pain perception and regulation in health and disease. Eur J Pain. 2005; 9(4):463-484. [PubMed: 15979027]

2. Atanassoff PG, Brull SJ, Zhang J, Greenquist K, Silverman DG, Lamotte RH. Enhancement of experimental pruritus and mechanically evoked dysesthesiae with local anesthesia. Somatosens Mot Res. 1999; 16(4):291-298. [PubMed: 10632026]

3. Babu R, Owens TR, Karikari IO, Moreno J, Cummings TJ, Gottfried ON, Bagley CA. Spinal cavernous and capillary hemangiomas in adults. Spine (Phila Pa 1976). 2013; 38(7):E423-430. [PubMed: 23354109]

4. Ballantyne JC, Loach AB, Carr DB. Itching after epidural and spinal opiates. Pain. 1988; 33(2):149_ 160. [PubMed: 2837714]

5. Baron R, Schwarz K, Kleinert A, Schattschneider J, Wasner G. Histamine-induced itch converts into pain in neuropathic hyperalgesia. Neuroreport. 2001; 12(16):3475-3478. [PubMed: 11733694]

6. Basbaum AI, Braz JM. Cell transplants to treat the "disease" of neuropathic pain and itch. Pain. 2016; 157(Suppl 1):S42-47. [PubMed: 26780378]

7. Binder A, Koroschetz J, Baron R. Disease mechanisms in neuropathic itch. Nat Clin Pract Neurol. 2008; 4(6):329-337. [PubMed: 18461071]

8. Bourane S, Duan B, Koch SC, Dalet A, Britz O, Garcia-Campmany L, Kim E, Cheng L, Ghosh A, Ma Q, Goulding M. Gate control of mechanical itch by a subpopulation of spinal cord interneurons. Science. 2015; 350(6260):550-554. [PubMed: 26516282]

9. Braz JM, Juarez-Salinas D, Ross SE, Basbaum AI. Transplant restoration of spinal cord inhibitory controls ameliorates neuropathic itch. J Clin Invest. 2014; 124(8):3612-3616. [PubMed: 25003193]

10. Carstens E. Responses of rat spinal dorsal horn neurons to intracutaneous microinjection of histamine, capsaicin, and other irritants. J Neurophysiol. 1997; 77(5):2499-2514. [PubMed: 9163372]

11. Carstens E, Akiyama T. Central Mechanisms of Itch. Curr Probl Dermatol. 2016; 50:11-17. [PubMed: 27578065]

12. Chiang MC, Hachisuka J, Todd AJ, Ross SE. Insight into B5-I spinal interneurons and their role in the inhibition of itch and pain. Pain. 2016; 157(3):544-545. [PubMed: 26716996]

13. Coghill RC, Talbot JD, Evans AC, Meyer E, Gjedde A, Bushnell MC, Duncan GH. Distributed processing of pain and vibration by the human brain. J Neurosci. 1994; 14(7):4095-4108. [PubMed: 8027764] 
14. Cohen OS, Chapman J, Lee H, Nitsan Z, Appel S, Hoffman C, Rosenmann H, Korczyn AD, Prohovnik I. Pruritus in familial Creutzfeldt-Jakob disease: a common symptom associated with central nervous system pathology. J Neurol. 2011; 258(1):89-95. [PubMed: 20725737]

15. Cohen-Adad J, Zhao W, Wald LL, Oaklander AL. 7T MRI of spinal cord injury. Neurology. 2012; 79(22):2217. [PubMed: 23183281]

16. Cowan A, Kehner GB, Inan S. Targeting Itch with Ligands Selective for kappa Opioid Receptors. Handb Exp Pharmacol. 2015; 226:291-314. [PubMed: 25861786]

17. Davidson S, Giesler GJ. The multiple pathways for itch and their interactions with pain. Trends Neurosci. 2010; 33(12):550-558. [PubMed: 21056479]

18. Davidson S, Moser H, Giesler G. Ascending Pathways for Itch. In: Carstens E, Akiyama T, editorsItch: Mechanisms and Treatment. Boca Raton (FL): 2014.

19. Devigili G, Eleopra R, Pierro T, Lombardi R, Rinaldo S, Lettieri C, Faber CG, Merkies IS, Waxman SG, Lauria G. Paroxysmal itch caused by gain-of-function Nav1.7 mutation. Pain. 2014; 155(9):1702-1707. [PubMed: 24820863]

20. Dey DD, Landrum O, Oaklander AL. Central neuropathic itch from spinal-cord cavernous hemangioma: a human case, a possible animal model, and hypotheses about pathogenesis. Pain. 2005; 113(1-2):233-237. [PubMed: 15621384]

21. Deza G, Gimenez-Arnau AM. Itch in Urticaria Management. Curr Probl Dermatol. 2016; 50:7785. [PubMed: 27578075]

22. Elsone L, Townsend T, Mutch K, Das K, Boggild M, Nurmikko T, Jacob A. Neuropathic pruritus (itch) in neuromyelitis optica. Mult Scler. 2013; 19(4):475-479. [PubMed: 22936333]

23. Forster C, Handwerker HO. Central Nervous Processing of Itch and Pain. In: Carstens E, Akiyama T, editorsItch: Mechanisms and Treatment. Boca Raton (FL): 2014.

24. Foster E, Wildner H, Tudeau L, Haueter S, Ralvenius WT, Jegen M, Johannssen H, Hosli L, Haenraets K, Ghanem A, Conzelmann KK, Bosl M, Zeilhofer HU. Targeted ablation, silencing, and activation establish glycinergic dorsal horn neurons as key components of a spinal gate for pain and itch. Neuron. 2015; 85(6):1289-1304. [PubMed: 25789756]

25. Han L, Ma C, Liu Q, Weng HJ, Cui Y, Tang Z, Kim Y, Nie H, Qu L, Patel KN, Li Z, McNeil B, He S, Guan Y, Xiao B, Lamotte RH, Dong X. A subpopulation of nociceptors specifically linked to itch. Nat Neurosci. 2013; 16(2):174-182. [PubMed: 23263443]

26. Han S, Soleiman MT, Soden ME, Zweifel LS, Palmiter RD. Elucidating an Affective Pain Circuit that Creates a Threat Memory. Cell. 2015; 162(2):363-374. [PubMed: 26186190]

27. Handwerker HO. Itch Hypotheses: From Pattern to Specificity and to Population Coding. In: Carstens E, Akiyama T, editorsItch: Mechanisms and Treatment. Boca Raton (FL): 2014.

28. Handwerker HO, Forster C, Kirchhoff C. Discharge patterns of human C-fibers induced by itching and burning stimuli. J Neurophysiol. 1991; 66(1):307-315. [PubMed: 1919673]

29. He Z, Ren M, Wang X, Guo Q, Qi X. Pruritus may be a common symptom related to neuromyelitis optica spectrum disorders. Mult Scler Relat Disord. 2017; 13:1-3. [PubMed: 28427688]

30. Hokfelt T. Neuropeptides in perspective: the last ten years. Neuron. 1991; 7(6):867-879. [PubMed: 1684901]

31. Hsieh JC, Hagermark O, Stahle-Backdahl M, Ericson K, Eriksson L, Stone-Elander S, Ingvar M. Urge to scratch represented in the human cerebral cortex during itch. J Neurophysiol. 1994; 72(6): 3004-3008. [PubMed: 7897505]

32. Inan S, Cowan A. Kappa opioid agonists suppress chloroquine-induced scratching in mice. Eur J Pharmacol. 2004; 502(3):233-237. [PubMed: 15476749]

33. Jansen NA, Giesler GJ Jr. Response characteristics of pruriceptive and nociceptive trigeminoparabrachial tract neurons in the rat. J Neurophysiol. 2015; 113(1):58-70. [PubMed: 25298386]

34. Jinks SL, Carstens E. Superficial dorsal horn neurons identified by intracutaneous histamine: chemonociceptive responses and modulation by morphine. J Neurophysiol. 2000; 84(2):616-627. [PubMed: 10938290]

35. Johanek LM, Meyer RA, Friedman RM, Greenquist KW, Shim B, Borzan J, Hartke T, LaMotte $\mathrm{RH}$, Ringkamp M. A role for polymodal C-fiber afferents in nonhistaminergic itch. J Neurosci. 2008; 28(30):7659-7669. [PubMed: 18650342] 
36. Johanek LM, Meyer RA, Hartke T, Hobelmann JG, Maine DN, LaMotte RH, Ringkamp M. Psychophysical and physiological evidence for parallel afferent pathways mediating the sensation of itch. J Neurosci. 2007; 27(28):7490-7497. [PubMed: 17626210]

37. Kardon AP, Polgar E, Hachisuka J, Snyder LM, Cameron D, Savage S, Cai X, Karnup S, Fan CR, Hemenway GM, Bernard CS, Schwartz ES, Nagase H, Schwarzer C, Watanabe M, Furuta T, Kaneko T, Koerber HR, Todd AJ, Ross SE. Dynorphin acts as a neuromodulator to inhibit itch in the dorsal horn of the spinal cord. Neuron. 2014; 82(3):573-586. [PubMed: 24726382]

38. Kiguchi N, Sukhtankar DD, Ding H, Tanaka K, Kishioka S, Peters CM, Ko MC. Spinal Functions of B-Type Natriuretic Peptide, Gastrin-Releasing Peptide, and Their Cognate Receptors for Regulating Itch in Mice. J Pharmacol Exp Ther. 2016; 356(3):596-603. [PubMed: 26669425]

39. Kini SP, DeLong LK, Veledar E, McKenzie-Brown AM, Schaufele M, Chen SC. The impact of pruritus on quality of life: the skin equivalent of pain. Arch Dermatol. 2011; 147(10):1153-1156. [PubMed: 21680760]

40. Ko MC, Lee H, Song MS, Sobczyk-Kojiro K, Mosberg HI, Kishioka S, Woods JH, Naughton NN. Activation of kappa-opioid receptors inhibits pruritus evoked by subcutaneous or intrathecal administration of morphine in monkeys. J Pharmacol Exp Ther. 2003; 305(1):173-179. [PubMed: 12649366]

41. Koch SC, Acton D, Goulding M. Spinal Circuits for Touch, Pain, and Itch. Annu Rev Physiol. 2017

42. Konold T, Bone G, Vidal-Diez A, Tortosa R, Davis A, Dexter G, Hill P, Jeffrey M, Simmons MM, Chaplin MJ, Bellworthy SJ, Berthelin-Baker C. Pruritus is a common feature in sheep infected with the BSE agent. BMC Vet Res. 2008; 4:16. [PubMed: 18445253]

43. Lagerstrom MC, Rogoz K, Abrahamsen B, Persson E, Reinius B, Nordenankar K, Olund C, Smith C, Mendez JA, Chen ZF, Wood JN, Wallen-Mackenzie A, Kullander K. VGLUT2-dependent sensory neurons in the TRPV1 population regulate pain and itch. Neuron. 2010; 68(3):529-542. [PubMed: 21040852]

44. LaMotte RH, Dong X, Ringkamp M. Sensory neurons and circuits mediating itch. Nat Rev Neurosci. 2014; 15(1):19-31. [PubMed: 24356071]

45. LaMotte RH, Shimada SG, Green BG, Zelterman D. Pruritic and nociceptive sensations and dysesthesias from a spicule of cowhage. J Neurophysiol. 2009; 101(3):1430-1443. [PubMed: 19144738]

46. Lanotte M, Panciani PP, Magistrello M, Naldi A, Fontanella M, Ducati A, Giordana MT. Central neuropathic itch as the presenting symptom of an intramedullary cavernous hemangioma: case report and review of literature. Clin Neurol Neurosurg. 2013; 115(4):454-456. [PubMed: 22709800]

47. Lennon VA, Kryzer TJ, Pittock SJ, Verkman AS, Hinson SR. IgG marker of optic-spinal multiple sclerosis binds to the aquaporin-4 water channel. J Exp Med. 2005; 202(4):473-477. [PubMed: 16087714]

48. Liu Q, Sikand P, Ma C, Tang Z, Han L, Li Z, Sun S, LaMotte RH, Dong X. Mechanisms of itch evoked by beta-alanine. J Neurosci. 2012; 32(42):14532-14537. [PubMed: 23077038]

49. Liu Q, Tang Z, Surdenikova L, Kim S, Patel KN, Kim A, Ru F, Guan Y, Weng HJ, Geng Y, Undem BJ, Kollarik M, Chen ZF, Anderson DJ, Dong X. Sensory neuron-specific GPCR Mrgprs are itch receptors mediating chloroquine-induced pruritus. Cell. 2009; 139(7):1353-1365. [PubMed: 20004959]

50. Liu Y, Abdel Samad O, Zhang L, Duan B, Tong Q, Lopes C, Ji RR, Lowell BB, Ma Q. VGLUT2dependent glutamate release from nociceptors is required to sense pain and suppress itch. Neuron. 2010; 68(3):543-556. [PubMed: 21040853]

51. Ma Q. Labeled lines meet and talk: population coding of somatic sensations. J Clin Invest. 2010; 120(11):3773-3778. [PubMed: 21041959]

52. McMahon SB, Koltzenburg M. Itching for an explanation. Trends Neurosci. 1992; 15(12):497501. [PubMed: 1282750]

53. Misery L, Bodere C, Genestet S, Zagnoli F, Marcorelles P. Small-fibre neuropathies and skin: news and perspectives for dermatologists. Eur J Dermatol. 2014; 24(2):147-153. [PubMed: 24509343] 
54. Misery L, Brenaut E, Le Garrec R, Abasq C, Genestet S, Marcorelles P, Zagnoli F. Neuropathic pruritus. Nat Rev Neurol. 2014; 10(7):408-416. [PubMed: 24912513]

55. Mishra SK, Hoon MA. The cells and circuitry for itch responses in mice. Science. 2013; 340(6135):968-971. [PubMed: 23704570]

56. Mochizuki H, Baumgartner U, Kamping S, Ruttorf M, Schad LR, Flor H, Kakigi R, Treede RD. Cortico-subcortical activation patterns for itch and pain imagery. Pain. 2013; 154(10):1989-1998. [PubMed: 23769719]

57. Mochizuki H, Tashiro M, Kano M, Sakurada Y, Itoh M, Yanai K. Imaging of central itch modulation in the human brain using positron emission tomography. Pain. 2003; 105(1-2):339346. [PubMed: 14499452]

58. Moser HR, Giesler GJ Jr. Itch and analgesia resulting from intrathecal application of morphine: contrasting effects on different populations of trigeminothalamic tract neurons. J Neurosci. 2013; 33(14):6093-6101. [PubMed: 23554490]

59. Moser HR, Giesler GJ Jr. Characterization of pruriceptive trigeminothalamic tract neurons in rats. J Neurophysiol. 2014; 111(8):1574-1589. [PubMed: 24478156]

60. Mu D, Deng J, Liu KF, Wu ZY, Shi YF, Guo WM, Mao QQ, Liu XJ, Li H, Sun YG. A central neural circuit for itch sensation. Science. 2017; 357(6352):695-699. [PubMed: 28818946]

61. Netravathi M, Saini J, Mahadevan A, Hari-Krishna B, Yadav R, Pal PK, Satishchandra P. Is pruritus an indicator of aquaporin-positive neuromyelitis optica? Mult Scler. 2017; 23(6):810-817. [PubMed: 27540000]

62. Nguyen MQ, Wu Y, Bonilla LS, von Buchholtz LJ, Ryba NJP. Diversity amongst trigeminal neurons revealed by high throughput single cell sequencing. PLoS One. 2017; 12(9):e0185543. [PubMed: 28957441]

63. Nilsson HJ, Psouni E, Carstam R, Schouenborg J. Profound inhibition of chronic itch induced by stimulation of thin cutaneous nerve fibres. J Eur Acad Dermatol Venereol. 2004; 18(1):37-43. [PubMed: 14678529]

64. Nilsson HJ, Schouenborg J. Differential inhibitory effect on human nociceptive skin senses induced by local stimulation of thin cutaneous fibers. Pain. 1999; 80(1-2):103-112. [PubMed: 10204722]

65. Oaklander AL. Mechanisms of pain and itch caused by herpes zoster (shingles). J Pain. 2008; 9(1 Suppl 1):S10-18. [PubMed: 18166461]

66. Oaklander AL. Neuropathic itch. Semin Cutan Med Surg. 2011; 30(2):87-92. [PubMed: 21767768]

67. Oaklander AL, Bowsher D, Galer B, Haanpaa M, Jensen MP. Herpes zoster itch: preliminary epidemiologic data. J Pain. 2003; 4(6):338-343. [PubMed: 14622691]

68. Oaklander AL, Cohen SP, Raju SV. Intractable postherpetic itch and cutaneous deafferentation after facial shingles. Pain. 2002; 96(1-2):9-12. [PubMed: 11932056]

69. Oklinski MK, Skowronski MT, Skowronska A, Rutzler M, Norgaard K, Nieland JD, Kwon TH, Nielsen S. Aquaporins in the Spinal Cord. Int J Mol Sci. 2016; 17(12)

70. Papoiu AD, Coghill RC, Kraft RA, Wang H, Yosipovitch G. A tale of two itches. Common features and notable differences in brain activation evoked by cowhage and histamine induced itch. Neuroimage. 2012; 59(4):3611-3623. [PubMed: 22100770]

71. Pereira MP, Muhl S, Pogatzki-Zahn EM, Agelopoulos K, Stander S. Intraepidermal Nerve Fiber Density: Diagnostic and Therapeutic Relevance in the Management of Chronic Pruritus: a Review. Dermatol Ther (Heidelb). 2016; 6(4):509-517. [PubMed: 27730494]

72. Rau KK, McIlwrath SL, Wang H, Lawson JJ, Jankowski MP, Zylka MJ, Anderson DJ, Koerber HR. Mrgprd enhances excitability in specific populations of cutaneous murine polymodal nociceptors. J Neurosci. 2009; 29(26):8612-8619. [PubMed: 19571152]

73. Reddy VB, Iuga AO, Shimada SG, LaMotte RH, Lerner EA. Cowhage-evoked itch is mediated by a novel cysteine protease: a ligand of protease-activated receptors. J Neurosci. 2008; 28(17):43314335. [PubMed: 18434511]

74. Ringkamp M, Schepers RJ, Shimada SG, Johanek LM, Hartke TV, Borzan J, Shim B, LaMotte RH, Meyer RA. A role for nociceptive, myelinated nerve fibers in itch sensation. J Neurosci. 2011; 31(42):14841-14849. [PubMed: 22016517] 
75. Roberson DP, Gudes S, Sprague JM, Patoski HA, Robson VK, Blasl F, Duan B, Oh SB, Bean BP, Ma Q, Binshtok AM, Woolf CJ. Activity-dependent silencing reveals functionally distinct itchgenerating sensory neurons. Nat Neurosci. 2013; 16(7):910-918. [PubMed: 23685721]

76. Rodriguez E, Sakurai K, Xu J, Chen Y, Toda K, Zhao S, Han BX, Ryu D, Yin H, Liedtke W, Wang F. A craniofacial-specific monosynaptic circuit enables heightened affective pain. Nat Neurosci. 2017; 20(12):1734-1743. [PubMed: 29184209]

77. Ross SE. Pain and itch: insights into the neural circuits of aversive somatosensation in health and disease. Curr Opin Neurobiol. 2011; 21(6):880-887. [PubMed: 22054924]

78. Ross SE, Hachisuka J, Todd AJ. Spinal Microcircuits and the Regulation of Itch. In: Carstens E, Akiyama T, editorsItch: Mechanisms and Treatment. Boca Raton (FL): 2014.

79. Ross SE, Mardinly AR, McCord AE, Zurawski J, Cohen S, Jung C, Hu L, Mok SI, Shah A, Savner EM, Tolias C, Corfas R, Chen S, Inquimbert P, Xu Y, McInnes RR, Rice FL, Corfas G, Ma Q, Woolf CJ, Greenberg ME. Loss of inhibitory interneurons in the dorsal spinal cord and elevated itch in Bhlhb5 mutant mice. Neuron. 2010; 65(6):886-898. [PubMed: 20346763]

80. Saper CB. The House Alarm. Cell Metab. 2016; 23(5):754-755. [PubMed: 27166934]

81. Schmelz M. Itch and pain differences and commonalities. Handb Exp Pharmacol. 2015; 227:285301. [PubMed: 25846624]

82. Schmelz M, Schmidt R, Bickel A, Handwerker HO, Torebjork HE. Specific C-receptors for itch in human skin. J Neurosci. 1997; 17(20):8003-8008. [PubMed: 9315918]

83. Schmelz M, Schmidt R, Weidner C, Hilliges M, Torebjork HE, Handwerker HO. Chemical response pattern of different classes of C-nociceptors to pruritogens and algogens. J Neurophysiol. 2003; 89(5):2441-2448. [PubMed: 12611975]

84. Seo WK, Kwon DY, Seo SH, Park MH, Park KW. Neuropathic pruritus following Wallenberg syndrome. Neurology. 2009; 72(7):676. [PubMed: 19221305]

85. Shelley WB, Arthur RP. Mucunain, the active pruritogenic proteinase of cowhage. Science. 1955; 122(3167):469-470. [PubMed: 13255877]

86. Sherrington CS. Observations on the scratch-reflex in the spinal dog. J Physiol. 1906; 34(1-2):150 .

87. Simone DA, Alreja M, LaMotte RH. Psychophysical studies of the itch sensation and itchy skin ("alloknesis") produced by intracutaneous injection of histamine. Somatosens Mot Res. 1991; 8(3):271-279. [PubMed: 1767623]

88. Simone DA, Ngeow JY, Whitehouse J, Becerra-Cabal L, Putterman GJ, LaMotte RH. The magnitude and duration of itch produced by intracutaneous injections of histamine. Somatosens Res. 1987; 5(2):81-92. [PubMed: 3423533]

89. Simone DA, Zhang X, Li J, Zhang JM, Honda CN, LaMotte RH, Giesler GJ Jr. Comparison of responses of primate spinothalamic tract neurons to pruritic and algogenic stimuli. J Neurophysiol. 2004; 91(1):213-222. [PubMed: 14715718]

90. Snyder LM, Ross SE. Itch and its inhibition by counter stimuli. Handb Exp Pharmacol. 2015; 226:191-206. [PubMed: 25861781]

91. Snyder LM, Ross SE, Belfer I. An SCN9A variant, known to cause pain, is now found to cause itch. Pain. 2014; 155(9):1677-1678. [PubMed: 24907406]

92. Stumpf A, Stander S. Neuropathic itch: diagnosis and management. Dermatol Ther. 2013; 26(2): 104-109. [PubMed: 23551367]

93. Sun S, Xu Q, Guo C, Guan Y, Liu Q, Dong X. Leaky Gate Model: Intensity-Dependent Coding of Pain and Itch in the Spinal Cord. Neuron. 2017; 93(4):840-853. e845. [PubMed: 28231466]

94. Sun YG, Chen ZF. A gastrin-releasing peptide receptor mediates the itch sensation in the spinal cord. Nature. 2007; 448(7154):700-703. [PubMed: 17653196]

95. Sun YG, Zhao ZQ, Meng XL, Yin J, Liu XY, Chen ZF. Cellular basis of itch sensation. Science. 2009; 325(5947):1531-1534. [PubMed: 19661382]

96. Todd AJ. Neuronal circuitry for pain processing in the dorsal horn. Nat Rev Neurosci. 2010; 11(12):823-836. [PubMed: 21068766] 
97. Togashi Y, Umeuchi H, Okano K, Ando N, Yoshizawa Y, Honda T, Kawamura K, Endoh T, Utsumi J, Kamei J, Tanaka T, Nagase H. Antipruritic activity of the kappa-opioid receptor agonist, TRK-820. Eur J Pharmacol. 2002; 435(2-3):259-264. [PubMed: 11821035]

98. Usoskin D, Furlan A, Islam S, Abdo H, Lonnerberg P, Lou D, Hjerling-Leffler J, Haeggstrom J, Kharchenko O, Kharchenko PV, Linnarsson S, Ernfors P. Unbiased classification of sensory neuron types by large-scale single-cell RNA sequencing. Nat Neurosci. 2015; 18(1):145-153. [PubMed: 25420068]

99. Vogelsang M, Heyer G, Hornstein OP. Acetylcholine induces different cutaneous sensations in atopic and non-atopic subjects. Acta Derm Venereol. 1995; 75(6):434-436. [PubMed: 8651018]

100. Yezierski RP, Liu S, Ruenes GL, Kajander KJ, Brewer KL. Excitotoxic spinal cord injury: behavioral and morphological characteristics of a central pain model. Pain. 1998; 75(1):141-155. [PubMed: 9539683]

101. Yoshimura M, Jessell T. Amino acid-mediated EPSPs at primary afferent synapses with substantia gelatinosa neurones in the rat spinal cord. J Physiol. 1990; 430:315-335. [PubMed: 1982314] 


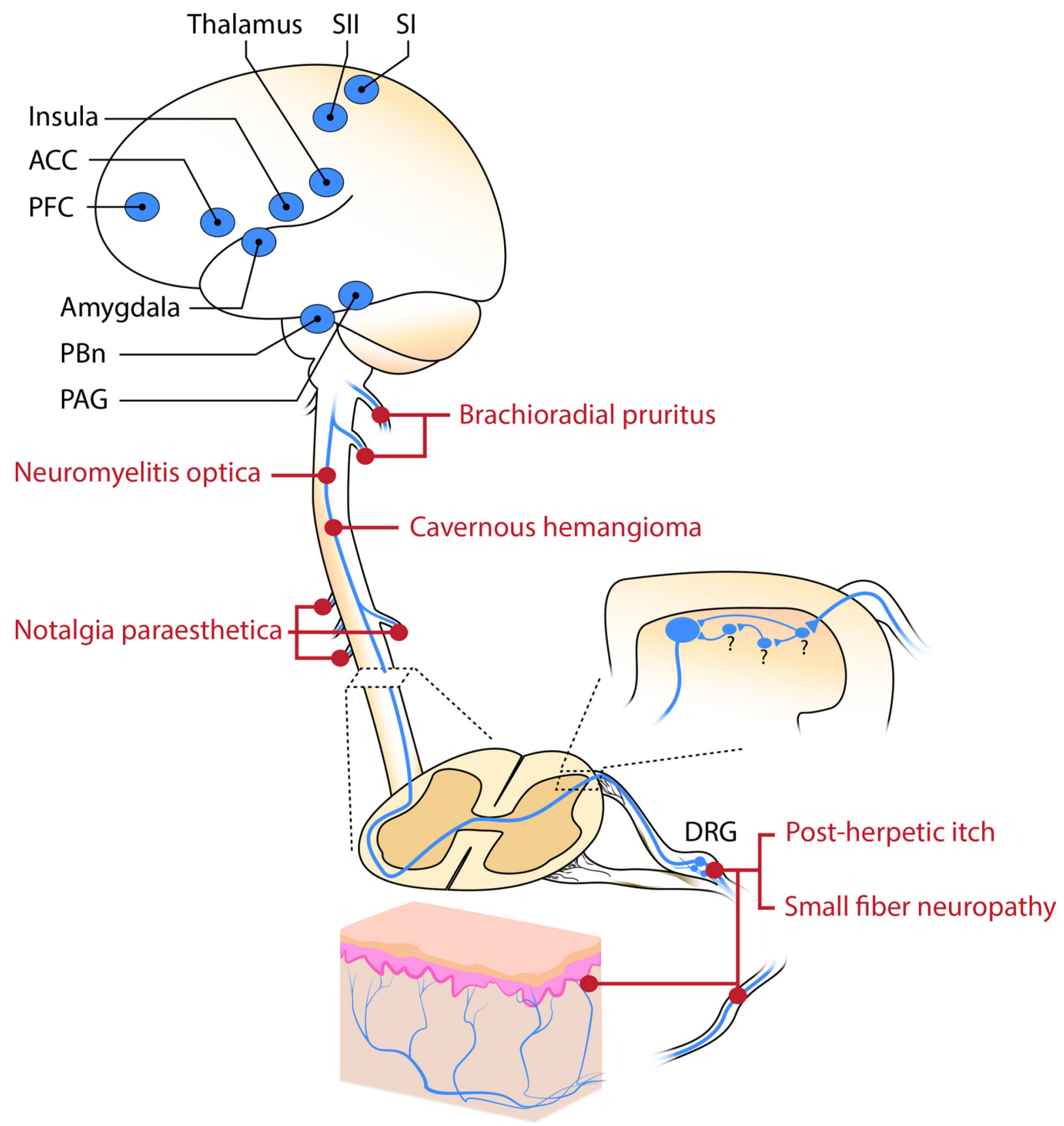

Figure 1.

Neural circuitry and brain regions involved in itch. Different types of neuropathic itch have been found to arise from lesions at different levels of the pathway. Abbrevions: ACC: anterior cingulate cortex; PFC: prefrontal cortex; SI: primary somatosensory cortex; SII: secondary somatosensory cortex; PBn: parabrachial nucleus; PAG: periaqueductal gray; DRG: dorsal root ganglia 

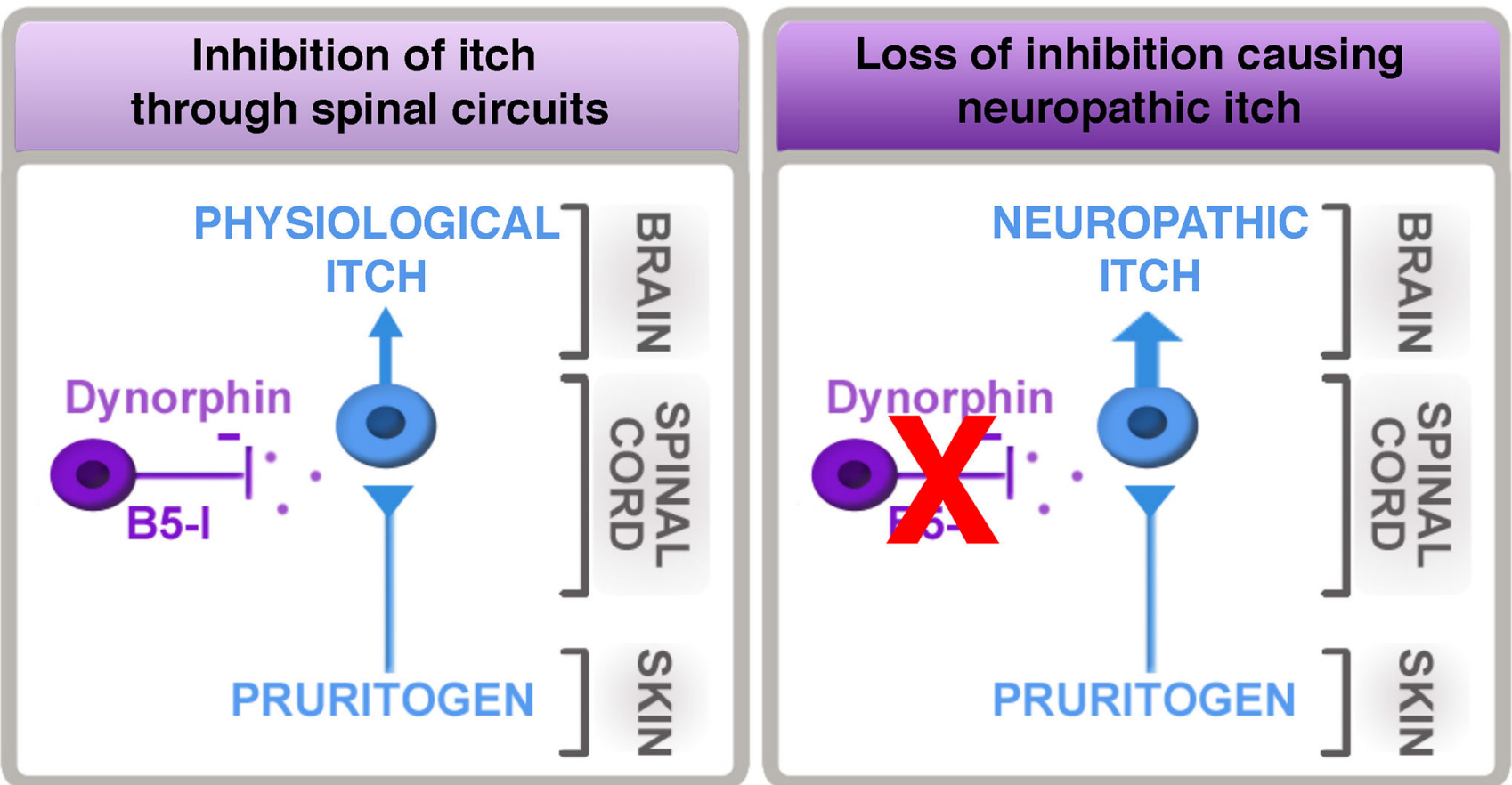

Figure 2.

Spinal circuits involving B5-I neurons and dynorphin normally limit itch. Loss of this inhibition results in severe neuropathic itch. 